\title{
Investigation of Flow Dynamics for a Microalgae Suspension in an Open Pond System
}

\author{
Nandita Barua Singha1, Ujjwal Kumar Deb2 ${ }^{2}$, Mushfique Shahriar ${ }^{3}$ \\ ${ }^{1}$ Department of Mathematics, Marine Fisheries Academy, Chittagong, Bangladesh \\ ${ }^{2}$ Department of Mathematics, Chittagong University of Engineering and Technology, Chittagong, Bangladesh \\ ${ }^{3}$ Department of Mechanical Engineering, Chittagong University of Engineering and Technology, Chittagong, Bangladesh \\ Email: nandita_b31@ymail.com, ukdeb03@gmail.com, tanim0907@gmail.com
}

How to cite this paper: Singha, N.B., Deb, U.K. and Shahriar, M. (2017) Investigation of Flow Dynamics for a Microalgae Suspension in an Open Pond System. American Journal of Computational Mathematics, 7, 195-207. https://doi.org/10.4236/ajcm.2017.73018

Received: March 21, 2017

Accepted: July 29, 2017

Published: August 1, 2017

Copyright ( $\odot 2017$ by authors and Scientific Research Publishing Inc. This work is licensed under the Creative Commons Attribution International License (CC BY 4.0).

http://creativecommons.org/licenses/by/4.0/ (c) (i) Open Access

\begin{abstract}
In the microalgae based biofuel technology, two main cultivation methods are available such as the Open pond system and the Closed photo bioreactor (PBR). The primary advantages of utilizing open raceway ponds are low production and maintenance cost. Though the open raceway ponds have been adjudged potentially cost effective, so many surrounding issues are involved to produce microalgae at a large scale that could make microalgae fuel cost competitive with the conventional petro oil. Many researchers have been studied so far to increase the efficiency of the cultivation methods without providing a proper mathematical model of flow dynamics inside the open raceway ponds. This paper presents a mathematical model to analyze the flow behavior of an open pond culture focusing the mixing factors by using a paddlewheel while the paddlewheel have its own unique dynamic characteristics. From our simulation we observed that the paddlewheel plays a vital role in mixing and the growth of microalgae. The velocity profiles, shear stress distributions are also studied at different parts of an open pond culture for a microalgae suspension.
\end{abstract}

\section{Keywords}

Biofuel, Microalgae, Open Pond System, Fluid Dynamics, Simulation

\section{Introduction}

The demand of energy and the Green House Effect (GHE) are the main two problems of the present world. In the $21^{\text {st }}$ century it has become unbearable with the time passing by. So to mitigate the GHE, the global warming problems and the depletion of fossil fuels, we need to find out an alternative energy sources to 
meet these massive problems over the next five decades [1]. Now, a day's biofuel is considered as one of the most alternative to fossil fuel in transportation sectors and has the capability to meet the energy demand as an alternative to gaseous and other liquids [2]. There are several advantages to produce biodiesel from microalgae such as capacity of fixing $\mathrm{CO}_{2}$ from the environment and treatment of the waste water [3]. Microalgae can mitigate $\mathrm{CO}_{2}$ from the environment which helps to reduce global warming issue because it has ability to tolerate gas pollutions than most other toxic chemicals [4].

Generally, biofuels are categorized in three generations. The first generation biofuels are crops plants such as sugar beet, sugar cane, palm oil, vegetables oil, soybean, animal fats etc. The second generation biofuels are non-edible parts of plants [5]. But in both cases, they yield a large cultivable area. Third generation biofuels are refers to various bio oil, biodiesel, renewable oil etc. Microalgae are the third generation biofuels which have no disadvantages like the first and the second generation biofuels [6].

At present new technologies and culture systems have been developed to produce biofuel from the microalgae. It is assumed to be the best source to meet the energy demand and to reduce the pressure on the petroleum based oil. Many researchers have accepted considerable interest in microalgae biofuel as a substitute of the fossil fuel. To get the best productivity from the microalgae, they have to go through rigorous cultivation process [7]. There are two types of culture systems. One is the traditional and simplest open pond system and the other is the closed photo bioreactors. Closed photo bioreactors are also many types: vertical column, flat panel, torus etc. They require small cultivable area, but the disadvantages are complicated mechanism to construct, operational cost and investment is high. Open pond facilitates mass cultivation of microalgae with cheap investment and operational expenses compared to closed system [8]. Between them the open pond systems are easy to construct and capital expense is low [9].

Microalgae are unicellular, photosynthetic microscopic organisms. They are very small plants generally size from $1-50$ micrometers and have no leaves or roots [10]. It is found in aquatic environments, damp places or shallow water sources [11]. Algae are constituted by carbohydrates, Nucleic Acids, Fats and proteins. Algae type microorganisms contain 40 percent fatty acids. These fatty acids can be turned into biodiesel [12]. This biodiesel has much popularity because it is nontoxic and almost has no effect in environment. There are different colors and groups of microalgae based on their taxonomy and it helps to mitigate surplus Carbon dioxide from the environment. To produce the chemical energy from the solar energy microalgae play a vital role promising biodiesel to their proficient absorption [13]. Nowadays microalgae have varied applications in food industries, chemical sector, pharmaceutical, and different poultry industries [14]. Generally three ingredients are needed for algae growth including Carbon-dioxide, Water and Sunlight [15]. Among them the sunlight is mandatory to support nutrients functioning properly [16]. To ensure the highest prod- 
uctivity from cultivation the sunlight reaching the suspension system must be kept within the tolerance level [17].

The open cultivation system has been used since 1950s. At present four major types of open pond are used such as raceway ponds, tanks, big ponds and circular ponds. They are different in their shapes, sizes and construction materials. One is the unmixed tank where nutrients and water are applied but have no mixing. In this system production is very low. Another system is called thin layer reactor where a paddle wheel controls the whole culture flow and surface to volume ratio is high [18]. Now a day's raceway pond system is most common which is the artificial, cheapest and established in different crop production areas. It looks like an oval-shaped and generally $0.3 \mathrm{~m}$ deep with recirculation channel built in concrete or plastic line. Depending on the size of a raceway pond, bends flow is guided by baffles placed. Paddlewheel maintains the flow continuity during daylight and prevents sedimentation. There are eight flat blades in a paddlewheel generally adjusted with the depth of the raceway pond. It works as like as propellers which divides the flow into two section [19].

Flow dynamics of the microalgae suspension can be obtained by the computational fluid dynamics method. Generally in the channel, the flow is assumed to be laminar flow to prevent the mortality rate of the cells in suspension and can be formulated by the Navier Stocks equation. Because of laminar flow the characteristics of flow field are Newtonian and fluid particle movement is absence near the wall of the domain. Thus on the wall no slip condition at the channels may be considered. Different velocities are occurring at the different portions of the flow for the variation of wall share rate [20]. In this study we focus on the dynamic behavior of the paddlewheel approve the adequate movement by mixing of $\mathrm{CO}_{2}$ and other antioxidant properties in the suspension. In the algae suspension mixture various parameters are affected which are studied numerically.

The rest of our paper is organized as follows. In Section 2 mathematical model and mesh design are established for the computational geometry. In Section 3, a single phase laminar flow model is established and numerical simulation results are analyzed. Finally a brief conclusion for this study is described in Section 4.

\section{Mathematical Model}

The main goal of this study is to improve our understanding of the flow dynamics of microalgae suspension by using single phase fluid model for an open pond system. Generally, in this system the paddlewheel controls the mixing velocity and prevent sedimentation. So the phenomenon due to the rotation of the paddle wheel is also our concern in this simulation study.

\subsection{Geometry}

In our study, the dimensions of the geometry are considered as per from the traditional raceway pond cultivation system. It is $10,000 \mathrm{~mm}$ in length and 2000 $\mathrm{mm}$ in width. The curvature radius of the inner periphery is about $1133 \mathrm{~mm}$. 
The semicircular baffles on the both sides are about $600 \mathrm{~mm}$ in radius. Its depth is about $500 \mathrm{~mm}$ [21]. The blade of the paddle wheel is in length $520 \mathrm{~mm}$ and the thickness is $0.2 \mathrm{~mm}$. Figure 1 shows the dimension of the computational domain of algae suspension in the raceway pond. Figure 2 and Figure 3 show the CAD model raceway pond and the paddlewheel respectively.

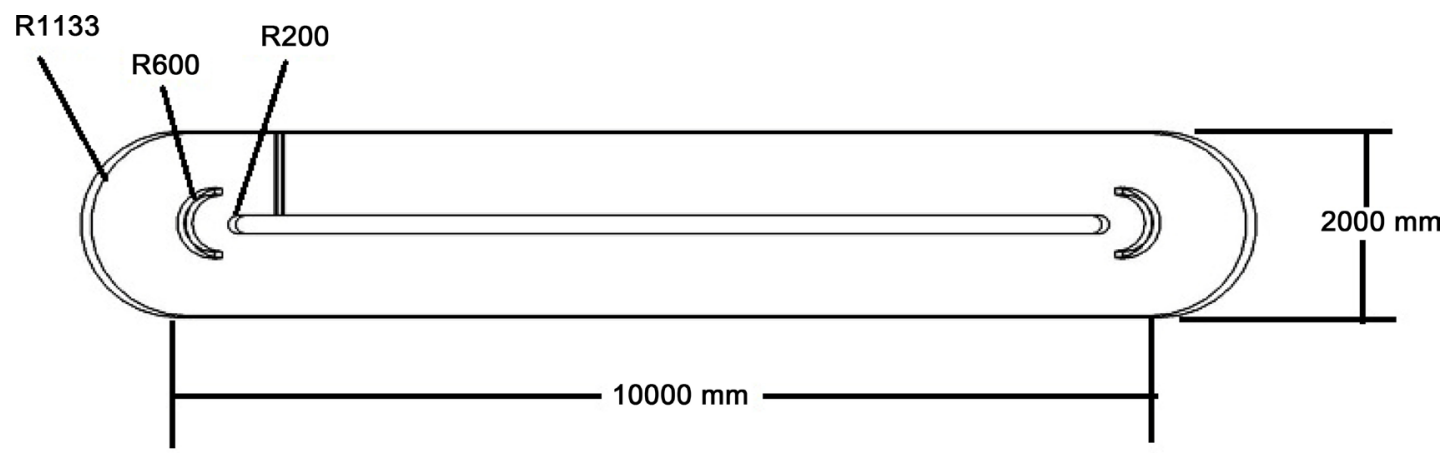

Figure 1. Dimensions of the algae suspension domain in the raceway pond.

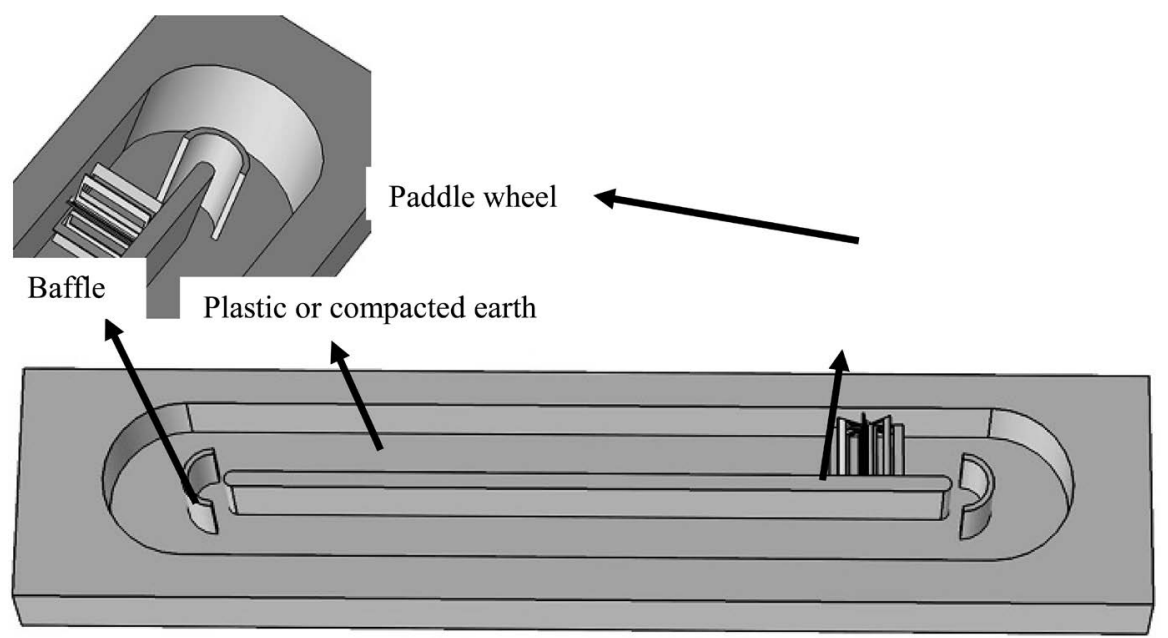

Figure 2. A CAD model of the raceway pond.

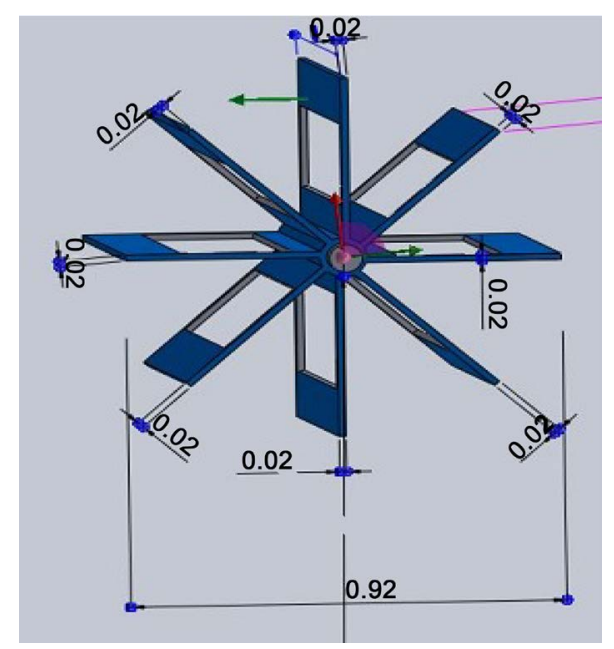

Figure 3. Design of a paddle wheel (dimensions are in $\mathrm{cm}$ ). 


\subsection{Computational Domain and Meshes}

The computational domain is placed horizontally along $\mathrm{XY}$ axis and $\mathrm{Z}$ axis is perpendicular to the flow. The surface area is $98.33 \mathrm{~m}^{2}$ while the working volume is $23.29 \mathrm{~m}^{3}$. In our simulation fine mesh design is considered with 673,800 elements and 489,180 degrees of freedom. Figure 4 and Figure 5 shows the computational domain and mesh design of the algae suspension respectively. The Table 1 shows the elements of mesh design while in the Table 2 shows the parameters of microalgae suspension.

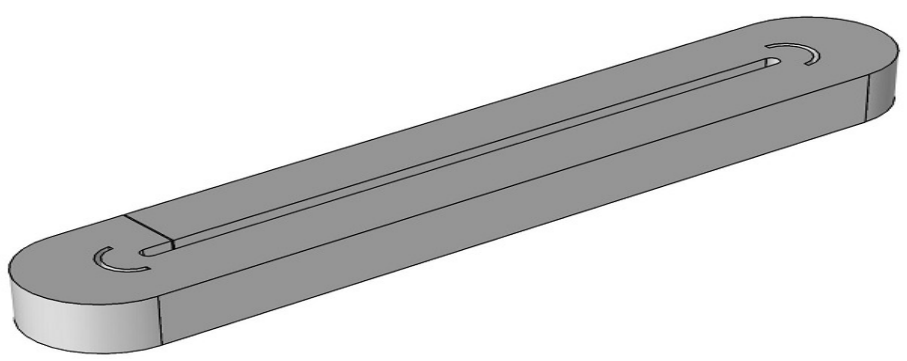

Figure 4. The computational domain of the algae suspension in the pond.

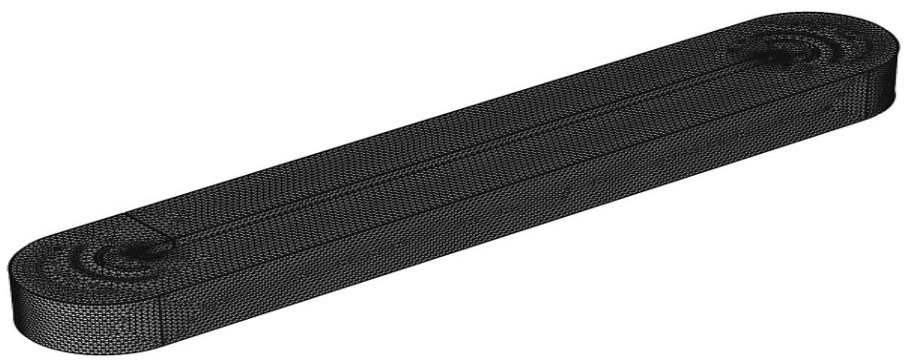

Figure 5. A fine mesh design of the computational domain.

Table 1. Number elements of mesh design for the computational domain.

\begin{tabular}{cc}
\hline Mesh elements & No. of elements \\
\hline Vertex elements & 40 \\
Boundary elements & 36,605 \\
Domain elements & 345,844 \\
Edge elements & 1551 \\
\hline
\end{tabular}

Table 2. The parameters used in our simulation.

\begin{tabular}{ccc}
\hline Name & Values & Description \\
\hline$g$ & $9.8 \mathrm{~m} / \mathrm{s}^{2}$ & Gravity acceleration \\
$\eta_{0}$ & 0.001 Pa.s & Water viscosity \\
$C_{0}$ & 0.55 & Constant parameter \\
$B$ & 200 & Constant parameter \\
$A$ & 1 & Constant parameter \\
$\mu_{\max }$ & $0.063[1 / \mathrm{h}]$ & Maximum growth rate \\
\hline
\end{tabular}




\subsection{Governing Equations}

The microalgae suspension inside the open pond is considered as an incompressible single phase Newtonian fluid. The flow of the suspension is governed by the continuity equation and the Navier-Stokes equation, which are as follows:

$$
\begin{gathered}
\frac{\partial \rho}{\partial t}+\nabla \cdot(\rho \boldsymbol{u})=0 \\
\rho \frac{\partial \boldsymbol{u}}{\partial t}+\rho(\boldsymbol{u} \cdot \nabla) \boldsymbol{u}=\nabla \cdot[-P \boldsymbol{I}+\tau]+\boldsymbol{F}
\end{gathered}
$$

where $\rho$ is the density of the suspension, $\boldsymbol{u}$ is the velocity, $p$ is the pressure, $\tau$ is the viscous stress tensor, $\boldsymbol{F}$ is the volume force, $I$ is the unit matrix.

The strain rate tensor related to the velocity is given by the following equation

$$
s=\frac{1}{2}\left(\nabla \boldsymbol{u}+(\nabla \boldsymbol{u})^{\mathrm{T}}\right)
$$

The viscous stress tensor in Equation (2) is given by

$$
\tau=2 \mu s-\frac{2}{3} \mu(\nabla \cdot u) I
$$

When the temperature variations in a flow are small, a single phase fluid can often be assumed as incompressible, that is $\rho$ is constant or nearly constant. This is the case for all liquids under normal conditions and also for gases at low velocity. For constant $\rho$ the continuity Equation (1) becomes

$$
\rho \nabla \cdot \boldsymbol{u}=0
$$

and the Equation (2) becomes

$$
\rho \frac{\partial \boldsymbol{u}}{\partial t}+\rho(\boldsymbol{u} \cdot \nabla) \boldsymbol{u}=-\nabla p I+\nabla \cdot\left(\mu\left(\nabla \boldsymbol{u}+(\nabla \boldsymbol{u})^{\mathrm{T}}\right)\right)-\frac{2}{3} \mu(\nabla \cdot \boldsymbol{u}) \boldsymbol{I}+\boldsymbol{F} .
$$

Equation (7) can be written in the simplest form

$$
\rho \frac{\partial \boldsymbol{u}}{\partial t}+\rho(\boldsymbol{u} \cdot \nabla) \boldsymbol{u}=\nabla \cdot\left[-p I+\mu\left(\nabla \boldsymbol{u}+(\nabla \boldsymbol{u})^{\mathrm{T}}\right)\right]+\boldsymbol{F} .
$$

Equation (8) can be written in the form

$$
\rho \frac{\partial \boldsymbol{u}}{\partial t}+\rho(\boldsymbol{u} \cdot \nabla) \mathbf{u}=\nabla \cdot \sigma+p \boldsymbol{g} .
$$

where $\sigma$ is the stress tensor and $g$ is the gravity. The stress tensor $\sigma$ can be expressed as

$$
\sigma=-p \boldsymbol{I}+2 \eta D(v)
$$

where $\eta$ is the viscosity of the fluid, $D(v)$ rate of deformation. The viscosity in Equation (10) is determined by

$$
\eta(t)=\eta_{0} \eta_{r}(t)
$$

The relative viscosity $\eta_{r}(t)$ relating to the concentration is then used and determined by 


$$
\eta_{r}(t)=1+\in c(t)
$$

where $\epsilon$ is the Einsteins coefficient [22]. The concentration function $c(t)$ in Equation (12) is given by the following logistic Equation [23].

$$
c(t)=c_{0}+\frac{A}{1+B \mathrm{e}^{\mu t}},
$$

where $\mu$ is the constant growth rate of microalgae cells and $C_{0}$ is the initial.

Concentration of the suspension and $A, B$ are constants.

\subsection{Boundary Condition}

In our study the adequate boundary conditions are important factor for the suspension. In our model no slip boundary condition is considered in inner side of the boundary wall. i.e. $\boldsymbol{u}=0$. In the inlet $\boldsymbol{u}=\boldsymbol{u}_{0}$ and the normal stress at the outlet can be described by the following equation

$$
\left[-p I+\mu\left(\nabla u+(\nabla u)^{\mathrm{T}}\right)\right] n=-f_{0} n
$$

\section{Numerical Results and Discussion}

The main goal of our simulation is to investigate the flow dynamics for an open pond system while the microalgae suspension circulates under the action of paddlewheel. Here we have used the COMSOL multiphysics simulation software version $4.2 \mathrm{a}$ to carry out our simulation. As we have taken time depended study, the time interval was $[0,100,3600]$ and the results are analyzed for the last time step. The inlet velocity of was taken as $U_{\text {in }}=0.5 \mathrm{~ms}^{-1}$ for the suspension flow.

Figure 6 represents the velocity profile at three different layers of the computational domain. It is found that the velocity magnitude is too much low at the lower layer (a) of the suspension because of friction between the domain boundary and lower layer fluid of the flow. In (b) shows that the velocity profile at the upper layer where the flow is in contact with the air. As a result the velocity is little bit higher compared to the lower layer. In (c) the highest velocity magnitude is observed in the middle layer of the domain compared to the upper and the lower layer flow. It is also velocity is generally found that the high in the straight portion of the pond. This profile shows that the inlet velocity is gradually increasing at the straight part of the raceway pond and decreasing at the U-loop area.

The velocity distribution graphs are shown in the Figure 7. We observed that when the flow passes through the straight part of the tube it form a parabolic shape in (a). However, the parabolic shape of the velocity is distorted around U-loop area which shown in (b).

In Figure 8, the shear stresses of the three layers have been observed from three different cross sections in one of the inner baffle's walls along the U-loop portion. The high share stress is found in the middle layer compared to the upper and lower layer of the flow. Through the pattern of the curves of the share rate is same at all three layers; initially a sharp up and sharp fall in found. 


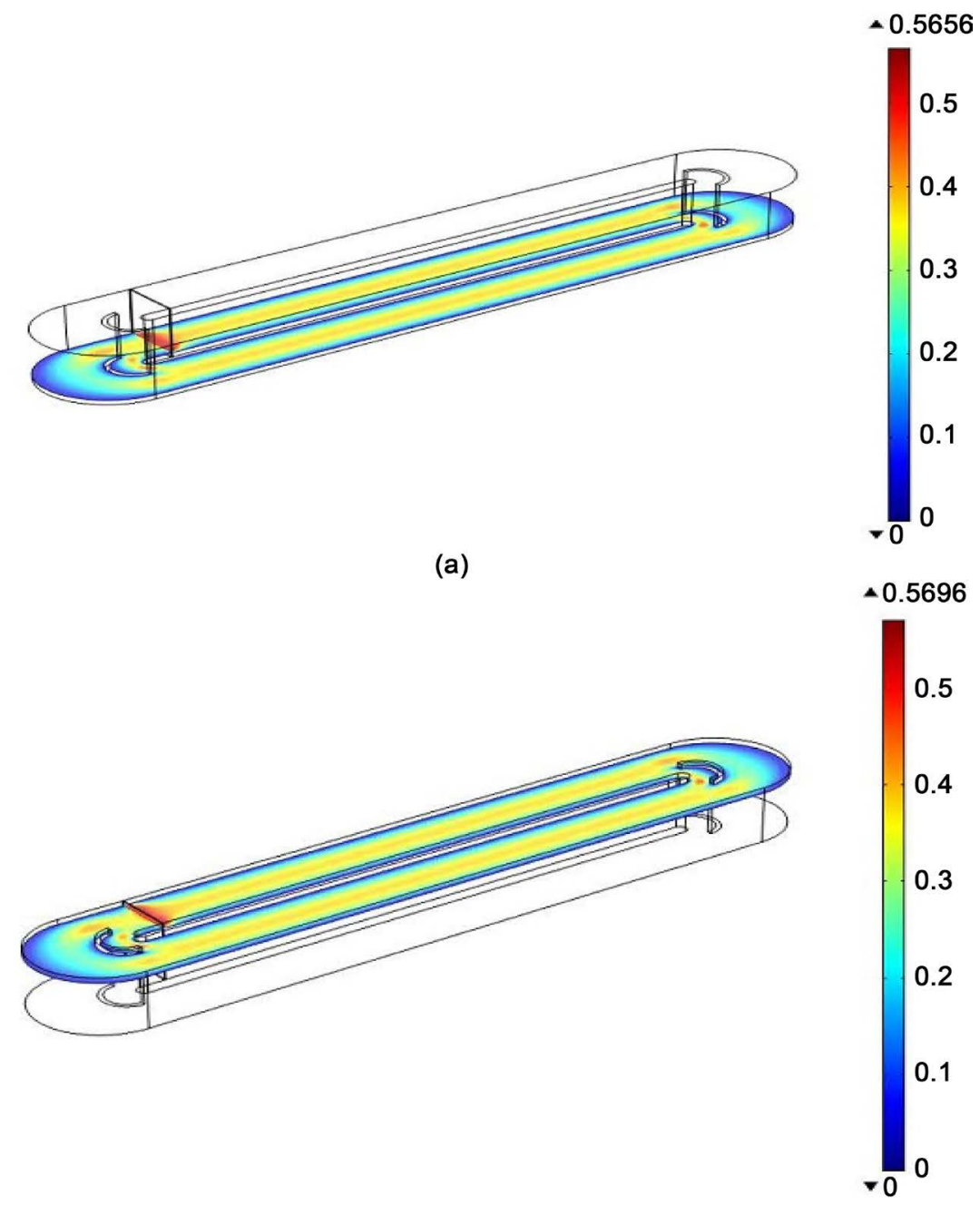

(b)

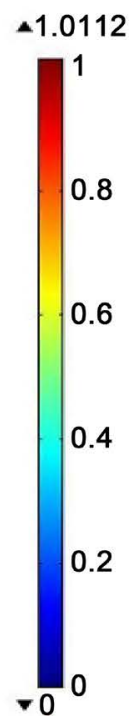

Figure 6. The velocity magnitude at three different layers of the computational domain of the suspension flow. (a) The velocity profile at lower the portion of the suspension; (b) The velocity profile at the upper portion of the suspension; (c) The velocity profile at the middle portion of the suspension. 


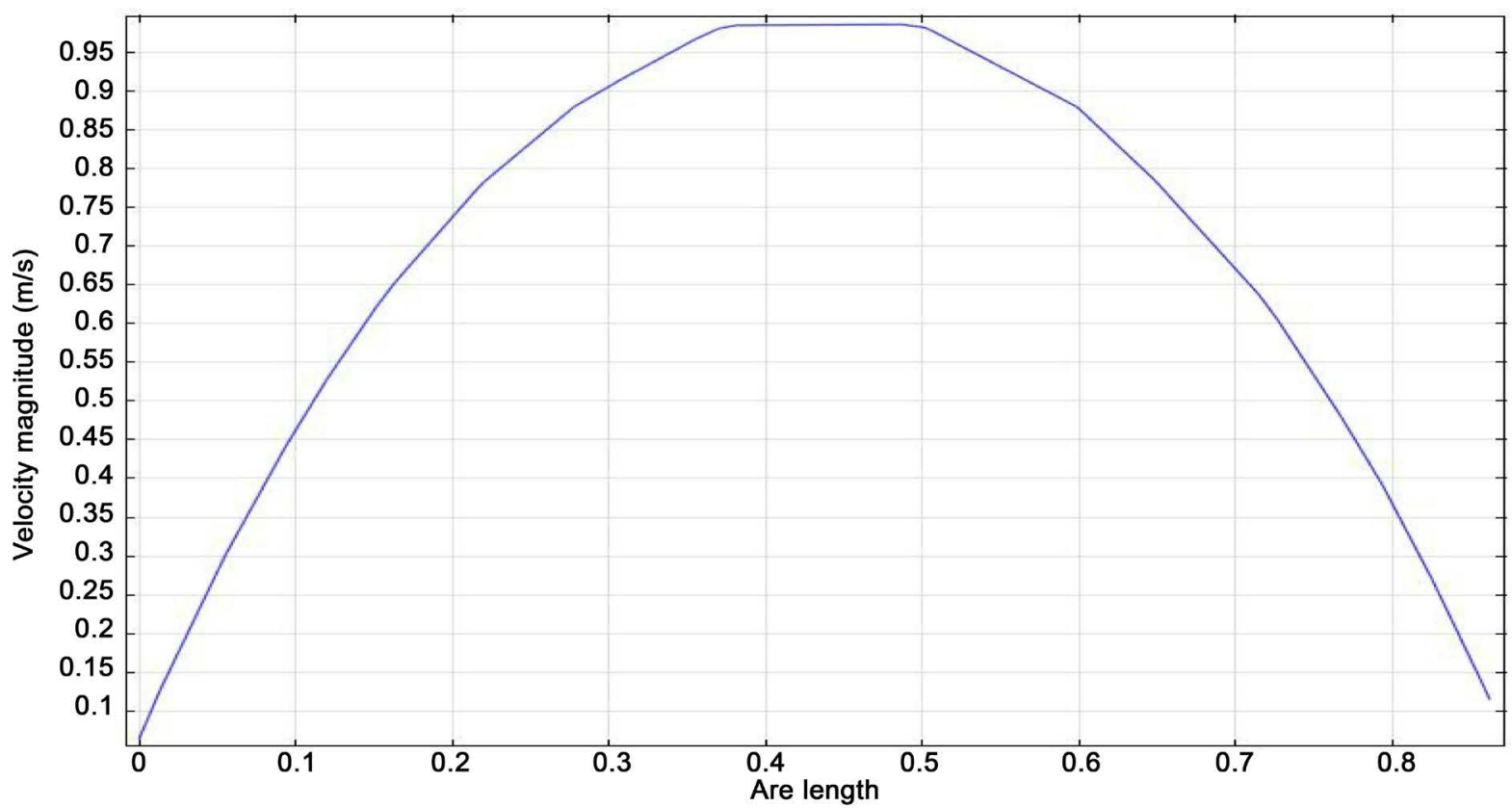

(a)

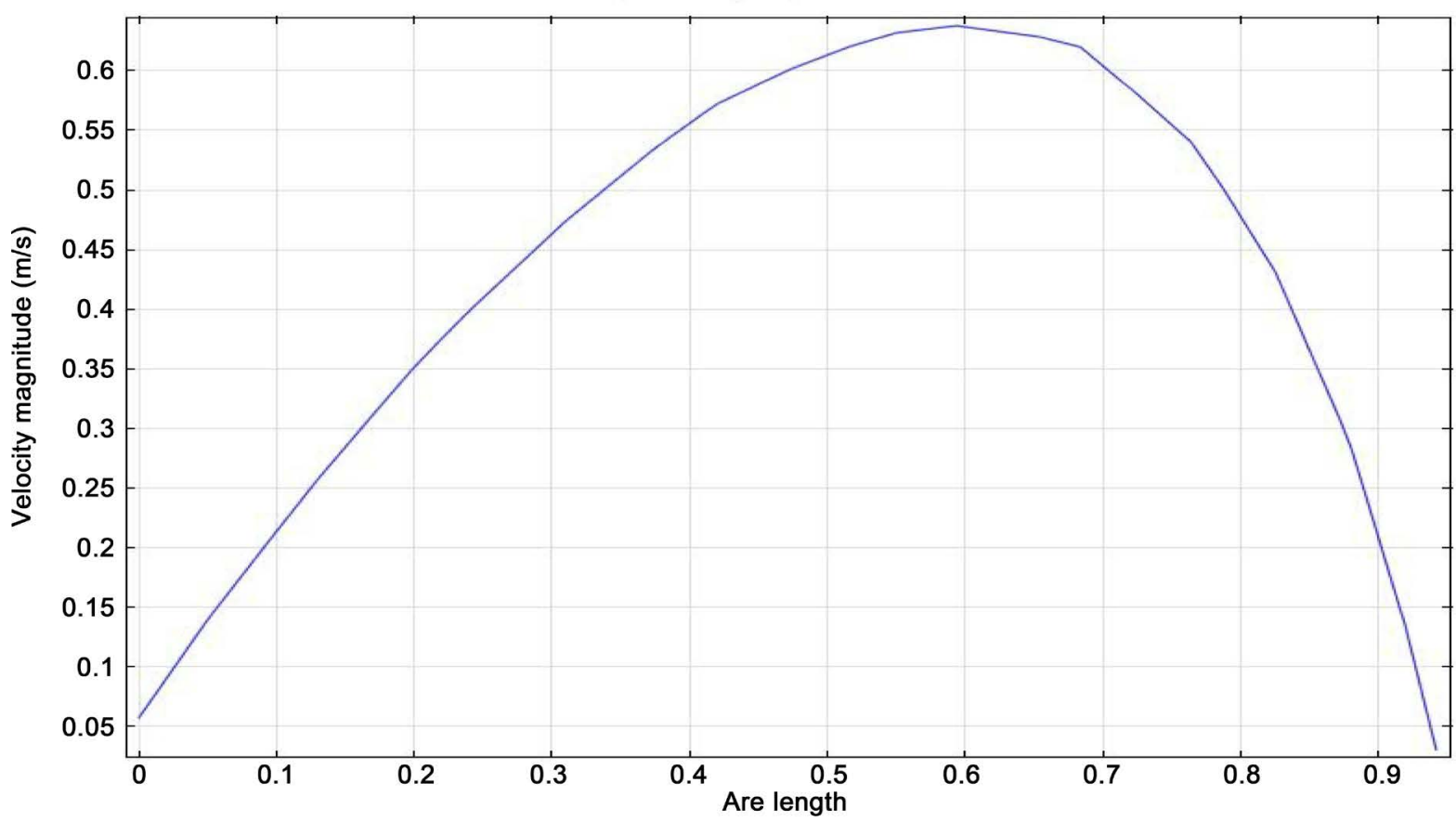

(b)

Figure 7. The velocity profile at different cross section of the straight part and the U-loop portion. (a) Velocity profile at a cross section of the stright portion of the domain; (b) The velocity profile at a cross section of the U-loop portion.

A uniform pressure drop at U-loop portion is shown in Figure 9. This phenomenon implies high pressure concentration profile during last moment in suspension. Figure 10 represents the graph of growth concentration of microalgae cell on the seventh day from 06.00 am to $18.00 \mathrm{pm}$. From our simulation we observed that the growth concentration of microalgae cell is increased slowly with time. 


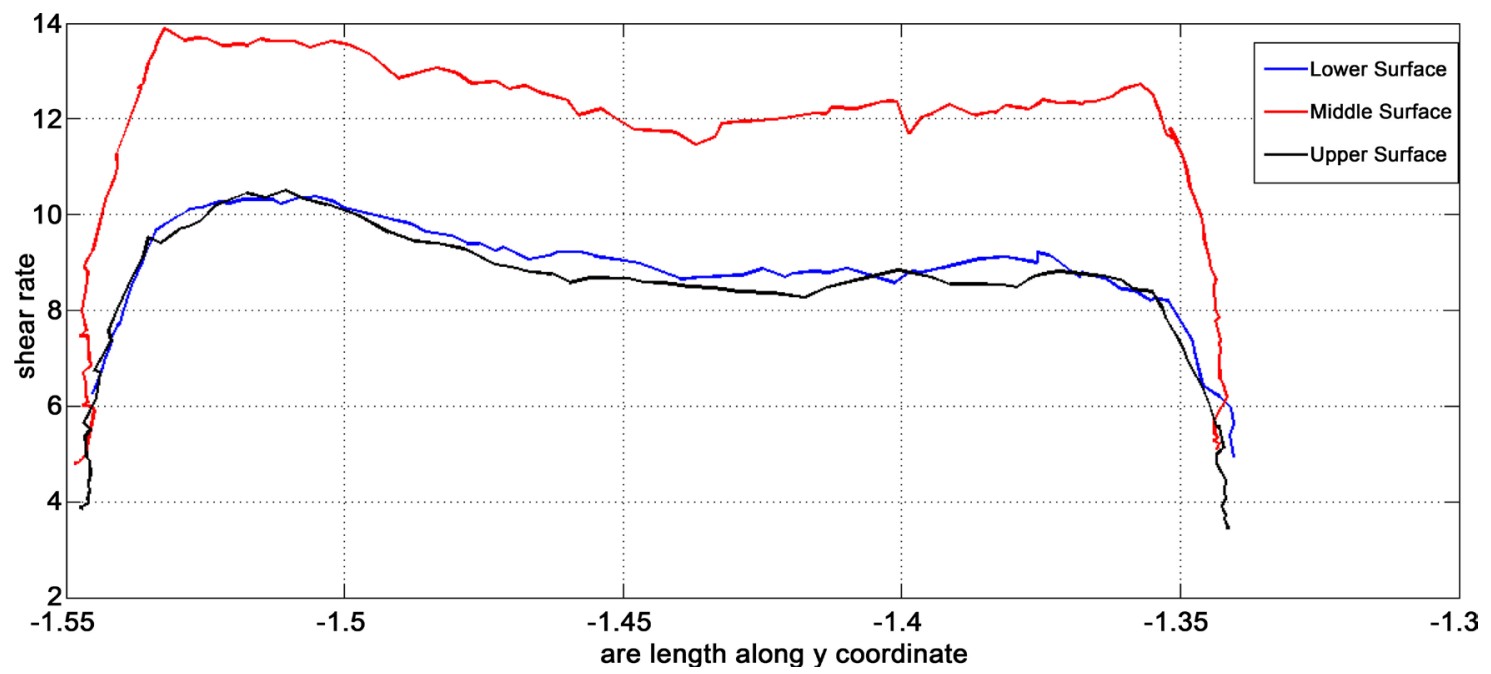

Figure 8. The share rate distribution along the raceway pond.

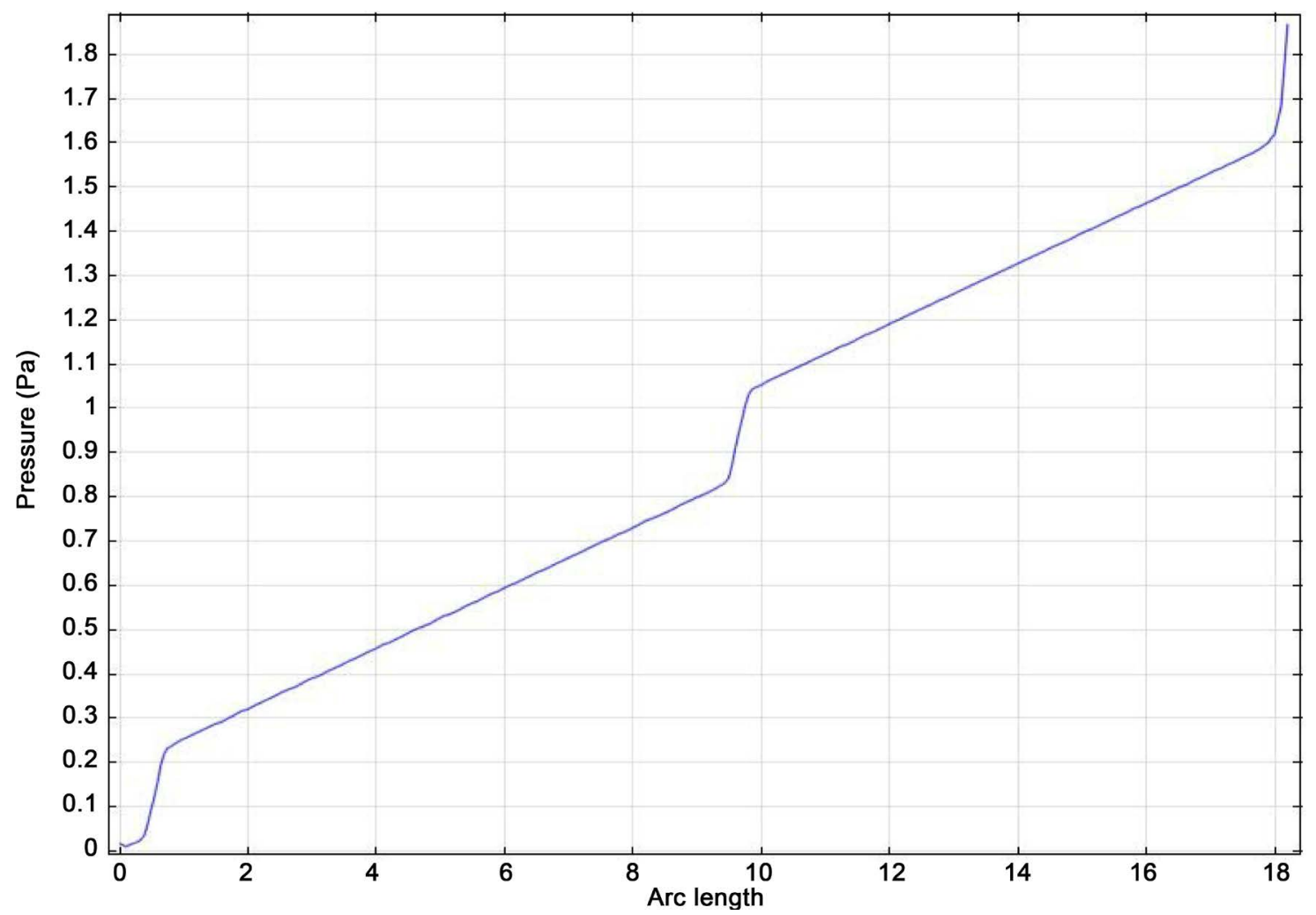

Figure 9. The pressure profile for the entire raceway pond.

\section{Conclusion}

In this study we analyzed the flow behavior of microalgae suspension in an open raceway pond system. The total surface area of the computational domain is $98.33 \mathrm{~m}^{2}$ and the volume is $23.29 \mathrm{~m}^{3}$. In our simulation a fine mesh design is considered with 673,800 elements and 489,180 degrees of freedom for grid sensitive analysis. From our simulation we found that the velocity of the suspension generally high in the middle part of the computational domain. The velocity 


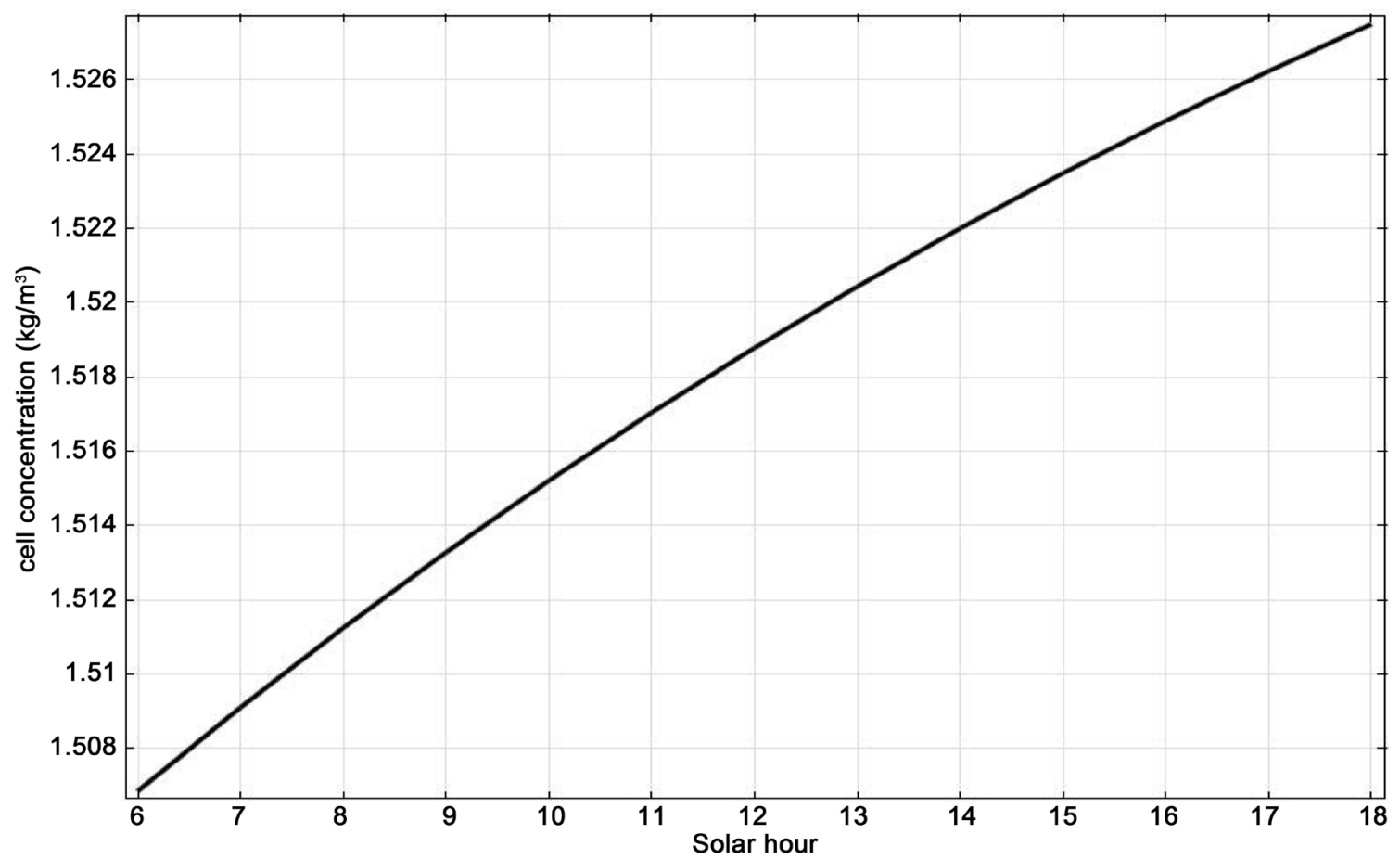

Figure 10. The growth concentration graph of microalgae cell.

magnitude is too much low at the lower layer of the suspension because of friction between boundary of the domain and lower layer of the flow. At the upper layer the flow is in contact with the air. As a result velocity is little bit higher compared to the lower layer. We also observed that this velocity is high at the straight portion than the U-loop portion in raceway pond. Consequently, the share rate distribution is responded with the flow velocity. The upper share rate is found in the middle of the domain compared to the lower and middle layers. A uniform pressure drop is found for the entire domain except a little fluctuation around U-loop area. We also found a good response for the cell growth by considering the increment of concentration of the suspension.

\section{Acknowledgements}

The authors thankfully acknowledge for the technical supports to the Centre of Excellence in Mathematics, Department of Mathematics, Mahidol University, Bangkok-10400, Thailand and the Simulation Lab, Department of Mathematics, Chittagong University of Engineering and Technology, Chittagong-4349, Bangladesh.

\section{References}

[1] Sudhakar, K. and Premalatha, M. (2012) Large-Scale Open Pond Algae Biomass Yield Analysis in India a Case Study. International Journal of Sustainable Energy, $33,1-12$

[2] Marsullo, M. (2014) Microalgae Growth and Biomass-To Synthetic Natural Gas Conversion through Hydrothermal Gasification: Dynamic Modeling of Cultivation 
Phase in Open Pond and Closed Photobioreactor. Master's Thesis, Universita degli studi di Padova, Padova.

[3] Rajvanshi, S. and Sharma, M.P. (2012) Microalgae: A Potential Source of Biodiesel. Journal of Sustainable Bioenergy System, 2, 49-59.

https://doi.org/10.4236/jsbs.2012.23008

[4] Cassidy, K.O. (2011) Evaluation Algal Growth at Different Temperatures. University of Kentucky, Lexington.

[5] Medipall, S.R.Y., Usoff, F.M., Banerjee, S. and Shariff, M. (2015) Microalgae as Sustainable Renewable Energy Feedstock for Biofuel. BioMed Research International, 2015, 13.

[6] Veillette, M., Chamoumi, M., Nikima, J., Fanchenx, N. and Heitz, M. (2012) Production of Biodiesel from Microalgae. University de Sherbrooke, Quebec.

[7] Derhulst, C.V. (2012) Microalgae Cultivation Systems. Utrecht University, Utrecht.

[8] Khanam, I.A. and Deb, U.K. (2016) Calculation of the Average Irradiance and the Microalgae Growth for a year at CUET, Bangladesh. American Journal of Computational Mathematics. 6, 237-244. https://doi.org/10.4236/ajcm.2016.63024

[9] Qudus, N.A. and Halim, S.Z. (2016) A Techno Economic Assessment of Algae production in Bangladesh. Ph.D. Thesis, Bangladesh University of Engineering \& Technology, Bangladesh.

[10] Guedes, A.C. and Malcata, F.X. (2012) Nutritional Value and Uses of Microalgae in Aquaculture.

[11] Hemalatha, A., Girija, K., Parthiban, C., Saranya, C. and Anantharaman, P. (2013) Antioxident Properties and Total Phenolic Content of Marine Diatom, Navicula Clavata and Green Microalgae, Chlorella Marine and Dunaliella Salina. Pelagia Research Library, 4, 151-157.

[12] Abodeely, J., Stevens, D., Ray, A., Schaller, K. and Newby, D. (2013) Algal Supply System Design-Hermonized Version. Idaho National Laboratory, Idaho Falls. https://doi.org/10.2172/1091350

[13] Blinova, L., Bartosova, A. and Gerulova, K. (2015) Cultivation of Microalgae (Chlorella Vugaris) for Biodisel Production. Faculty of Meterials Science and Technology in Trnava, Slovak University of Technology in Bratislava, Bratislava.

[14] Shahriar, M., Monir, M.I. and Deb, U.K. (2016) Comparative Analysis of Hydrodynamics Behaviour of Microalgae Suspension Flow in Circular, Square and Hexagonal Photobioreactors. American Journal of Computational Mathematics, 6, 320 335. https://doi.org/10.4236/ajcm.2016.64033

[15] Wu, L. and Song, Y.H. (2009) Numerical Investigation of Flow Characteristics and Irradiance History in a Novel Photobioreactor. African Journal of Biotechnology, 8, 4672-4679.

[16] Muhit, I.B., Baidya, D. and Nahid, N. (2014) Prospect of Algal Biodiesal Production in Bangladesh: Overview from Develop Countries. IOSR Journal of Mechanical Engineering, 11, 49-54. https://doi.org/10.9790/1684-11134954

[17] Chisti, Y. (2007) Biodiesel from Microalgae. Biotecnology Advances, 25,294-306. https://doi.org/10.1016/j.biotechadv.2007.02.001

[18] Brennan, L. and Owende, P. (2010) Biofuel from Microalgae-A Review of Technologies for Production, Processing, and Extractions of Biofuels and Co-Products. Renewable and Sustainable Energy Reviews, 14, 557-577. https://doi.org/10.1016/j.rser.2009.10.009 
[19] Chisti, Y. (2016) Large-Scale Production of Algae Biomass: Raceway Ponds. Springer International Publishing Switzerland, Berlin, 21-40.

[20] Soulies, A., Pruvost, J., Castelain, C. and Burghelea, T. (2016) Microscopic Flows of Suspensions of the Green Non-Motile Chlorella Micro-Alga at Various Volume Fractions: Applications to Intensified Photobioreactors. Journal of Non-Neotonian Fluid Machanics, 231, 91-101. https://doi.org/10.1016/j.jnnfm.2016.03.012

[21] Lin, Y.H. (2014) Study on Raceway Pond for Microalgae Cultivation System. Master's Thesis, Department of Marine Environment and Engineering, National Sun Yat-sen University, Gaoxiong.

[22] Einstein, A. (1906) Einenueu Bestimmung der Molekuldimensionen. Annalen der Physik, 324, 289-306. https://doi.org/10.1002/andp.19063240204

[23] Deb, U.K., Chayantrakom, K. and Lenbury, Y. (2012) Comparison of Single-Phase and Two-Phase Flow Dynamics in the HLTP for Microalgae Culture. International Journal of Mathematics and Computers in Simulation, 6, 496-503.

\section{Scientific Research Publishing}

\section{Submit or recommend next manuscript to SCIRP and we will provide best} service for you:

Accepting pre-submission inquiries through Email, Facebook, LinkedIn, Twitter, etc. A wide selection of journals (inclusive of 9 subjects, more than 200 journals) Providing 24-hour high-quality service User-friendly online submission system Fair and swift peer-review system Efficient typesetting and proofreading procedure Display of the result of downloads and visits, as well as the number of cited articles Maximum dissemination of your research work

Submit your manuscript at: http://papersubmission.scirp.org/ Or contact ajcm@scirp.org 